\title{
How does social support contribute to engaging Post-PhD experience?
}

\author{
Pyhältö, Kirsi
}

2017

Pyhältö , K , McAlpine , L , Peltonen , J \& Castello , M 2017 , ' How does social support

contribute to engaging Post-PhD experience? ' , European Journal of Higher Education , vol.

7 , no. 4 , pp. 373-387 . https://doi.org/10.1080/21568235.2017.1348239

http://hdl.handle.net/10138/308676

https://doi.org/10.1080/21568235.2017.1348239

unspecified

acceptedVersion

Downloaded from Helda, University of Helsinki institutional repository.

This is an electronic reprint of the original article.

This reprint may differ from the original in pagination and typographic detail.

Please cite the original version. 


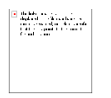

\section{How does social support contribute to engaging Post-PhD experience?}

\begin{tabular}{|c|c|}
\hline Journal: & European Educational Research Journal \\
\hline Manuscript ID & Draft \\
\hline Manuscript Type: & General submission \\
\hline Kcywords: & $\begin{array}{l}\text { Social support, supervisory support, Researcher community support, Post } \\
\text { PhD researchers, Cross-country comparison }\end{array}$ \\
\hline Abstract: & $\begin{array}{l}\text { Social support from the supervisor and the researcher community has been } \\
\text { identified as one of the determinants for successful completion of doctoral } \\
\text { studies. Still surprisingly little known about the function of social support } \\
\text { for early career Post-PhD researchers. Even less is known about the } \\
\text { individual variation in experienced social support among Post-PhD } \\
\text { researchers. This study explores the function of social support in terms of } \\
\text { experienced research engagement, burnout and abandonment intentions } \\
\text { among Post-PhD researchers. Altogether, } 282 \text { Post-PhD researchers from } \\
\text { UK and Spanish universities completed the survey. The cluster analysis was } \\
\text { applied. Results show that the majority of participants experienced high } \\
\text { levels of supervisory and researcher community support. Researchers } \\
\text { representing an Adequate Support profile were less likely to experience } \\
\text { burnout or to consider abandonment; they also experienced a higher } \\
\text { degree of research engagement than their less fortunate counterparts. } \\
\text { Further, Post PhD researchers working in research groups were more likely } \\
\text { to display the Adequate Support profile than those working primarily on } \\
\text { their own. Strikingly, scientists were more likely than social scientists to be } \\
\text { represented in the Reduced Support profile. Interestingly, there were no } \\
\text { statistically significant differences between the UK and Spanish Post-PhD or } \\
\text { female and male researchers in support profiles. }\end{array}$ \\
\hline
\end{tabular}

\section{SCHOLARONE ${ }^{\text {m }}$}

Manuscripts 


\title{
How does social support contribute to engaging Post-PhD experience?
}

\begin{abstract}
Social support from the supervisor and the researcher community has been identified as one of the determinants for successful completion of doctoral studies. Still surprisingly little known about the function of social support for early career Post-PhD researchers. Even less is known about the individual variation in experienced social support among Post-PhD researchers. This study explores the function of social support in terms of experienced research engagement, burnout and abandonment intentions among Post-PhD researchers. Altogether, $282 \mathrm{Post}-\mathrm{PhD}$ researchers from UK and Spanish universities completed the survey. The cluster analysis was applied. Results show that the majority of participants experienced high levels of supervisory and researcher community support. Researchers representing an Adequate Support profile were less likely to experience burnout or to consider abandonment; they also experienced a higher degree of research engagement than their less fortunate counterparts. Further, Post-PhD researchers working in research groups were more likely to display the Adequate Support profile than those working primarily on their own. Strikingly, scientists were more likely than social scientists to be represented in the Reduced Support profile. Interestingly, there were no statistically significant differences between the UK and Spanish Post-PhD or female and male researchers in support profiles.

Keywords: social support, supervision, researcher community, post-doctoral students, burnout, engagement, abandonment
\end{abstract}

\section{Introduction}

Life after earning a $\mathrm{PhD}$ is not easy. Post-PhD researchers are a highly accomplished group of early career researchers (Boeren et al. 2015), yet they need to manage several challenges, including a high level of competition, a fragmented career path, and even a risk of unemployment due to the increased number of doctoral degree holders (Authors, et al., 2016; Åkerlind, 2005), to establish themselves as scholars. The challenges may turn into stressors such as high level of demands, low level of support, and poor-quality relationships, eventually leading to career abandonment ${ }^{1}$ (Kinman and Court, 2010). Among these resources, researcher community, including peers, supervisor(s) and researcher networks are suggested to play a crucial role (Browning et al., 2011; McAlpine, 2016;

\footnotetext{
${ }^{1}$ In this article we use the term career abandonment to refer Post-PhD. researchers' decision to change their career from their current academic career to non-academic career or other alternative career.
} 
Scaffidi and Berman, 2011). Supervisory support has, for instance, been shown to contribute to Post-PhD researcher track record and research productivity (Scaffidi and Bergman, 2011), whereas strong integration into the researcher community has been shown to contribute to Post-PhD researcher future employment (Jackson and Michelson, 2015). Post-PhD researchers' experiences of community support, and hence outcomes associated with support may, however, differ even within the same research group, across different disciplines, between countries or depend on gender (Auriol, 2010; Laudel and Gläser, 2008; Dever, et al., 2008). Accordingly, Post-PhD researchers' social resources to cope with the challenges provided by the career phase are likely to vary across researchers, resulting in increased or reduced risk for negative post-doctoral experience and abandonment. To be able to provide useful information to Post-PhD researchers, to develop more functional support systems for them, and to identify researchers at risk as early as possible, we need to gain a better understanding about the kinds of experience profiles that are associated with increased risk for negative Post-PhD experience and career abandonment. However, evidence about the association between post-PhD researcher social support profiles, and increased or reduced risk for burnout and career abandonment is still scarce (Pearson et al., 2011). This paper explores Post$\mathrm{PhD}$ researchers' social support profiles, particularly the association with experienced burnout, research engagement and abandonment intentions by applying a person centered approach. Hence, instead of exploring association between the support variables we focus on exploring variation between the individuals in experiences supervisory and researcher community support by utilizing profile analysis.

\section{Supervisory and researcher community support}

Social support refers to the resources both perceived to be available, and used by the Post-PhD researcher in the social environment. This entails both formal and informal relationships, both dyadic and group relationships within the researcher community, with peers, $\mathrm{PhD}$ students, supervisor(s), other staff members (Vekkaila, et. al., 2016) as well as research groups, international researcher networks or special interest groups, and relationships with institutional representatives, for example funding agencies. Social support is a meta-construct comprising emotional, informational and instrumental forms (see Cobb 1976; House 1981; Väisänen, et al., 2016). Emotional support refers to empathy, trust, listening, caring and belonging to a network of researcher community with mutual obligation, whereas informational support is characterized by information, such as advice, feedback, affirmation, suggestions, and problem solving that enables a post- $\mathrm{PhD}$ researcher to cope with the problems faced. Instrumental support such as time, labour or 
providing funding from different sources or facilities, directly helps post- $\mathrm{PhD}$ researchers to manage their work.

High quality social support has been identified as a central determinant of optimal Post-PhD researcher experience, and related outcomes such as productivity in terms of number of publications (Authors, et al., in press; Horta, 2009; Jackson and Michelson, 2015; Author, 2014; Puljak and Sharif, 2009; Åkerlind, 2005; 2009) - these studies generally name the source of support but not the type of support. Particularly, important for sufficient support utilization is how post-PhD researchers a) perceive the social resources available and b) use them. Supervisor(s), and other members of the post- $\mathrm{PhD}$ researcher's immediate researcher community typically provide the primary source of social support (e.g., Author, 2014). A nurturing research environment, acknowledgement from the researcher community, broad researcher networks and strong integration into the researcher community have been associated with increased productivity, employment and overall satisfaction with post-doctoral experience (Horta, 2009; Scaffidi and Berman, 2011). Evidence on the function of supervisory support is less consistent. A number of qualitative studies suggest that supervisory support can have a positive (as well as negative) influence on Post-PhD researcher experience (e.g. Chen, et al., 2015; Scaffidi and Bergman, 2011); specifically, instrumental support, such as writing recommendations and providing access to institutional resources including infrastructure or opportunities to gain teaching experience (Chen, et al., 2015; Rybarczyk, et al., 2011; Åkerlind, 2009). However, in some quantitative studies no such association has been found (Jackson and Michelson, 2015) or is quite small ( see e.g. Eby et al.'s (2008) literature review on academic and non-academic mentoring). A reason for the less consistent findings in terms of supervisory support and positive Post-PhD researcher attributes may be that the effect of the supervisory support may be mediated via expansion of researcher networks rather than directly. While supervisors can be a central resource for enculturation into a new researcher community and introduce newcomers into their own professional networks, as advanced early career researchers, post- $\mathrm{PhD}$ researchers also have their own researcher networks that they can utilize as sources of support. Moreover, potential sources of social support are not limited to the researcher community, but are often extended to close friends and family, specifically the support and co-investment of the significant others, close family and friends as an asset in pursuing an academic career (Chen, et al., 2015). In turn, lack of such support is often perceived as problematic, and occasionally leads to abandonment (Author, 2015; Author, 2016). 
The sources and needed forms of support can vary depending on individual competences, career phase and tasks at hand. There are some indicators that peers may provide a central source of emotional support whereas supervisors and other senior members of the researcher community are emphasised as primary sources of informational and instrumental support (Author, et. al., 2014; Vekkaila, et al., 2016). The availability of social support is a crucial, but not in itself sufficient, determinant for positive Post-PhD experience. The perceived fit between the needed and provided support is also a central ingredient in the Post-doctoral experience (Vekkaila, et al., 2016). To be functional the provided support should promote coping with the particular problem being faced (Cohen and McKay 1984; Helgeson and Gottlieb 2000), i.e., the support being offered should match the type of problem being faced to be effective. Also, the appropriateness of the social support, the reciprocity of interaction and the roles of the giver and receiver of the support are important determinants for the experience of support and related outcomes (Cohen and Syme 1985). If the challenges faced exceed the early career researcher's resources to cope with them, this is likely to increase experienced stress (Author et al., 2013; Baker and Pifer, 2015). In general, experiencing social support has been associated with more engaging Post-PhD research experience whereas lack of support, and diminishing feedback reduced experienced engagement in academic activities (Vekkaila, et. al., 2016). Interestingly, reciprocal support, and particularly giving support to others was rarely reported by Post-PhD researchers (Vekkaila, et al., 2016). To sum up, prior research suggests that different sources and elements of social support can play complementary but also sometimes even contradictory roles in Post-PhD researcher experience. Thus, variation among Post$\mathrm{PhD}$ researchers in experienced social support from the supervisor and researcher community is likely to occur, increasing the differences in post- $\mathrm{PhD}$ researcher ability to cope with the stressors of this highly challenging career phase.

Interrelation between the social support research engagement and burnout experiences among the Post-PhD. researchers

Social support has been shown to buffer negative effects of prolonged stress (Chan, 2002), and promote work engagement across a wide range of occupational settings (Billet, 2001; Scaffidi and Berman, 2011). There is also a growing body of evidence suggesting that sufficient researcher community and supervisory support plays a central role in an engaged Post-PhD experience characterized by experiences of vigor, dedication and absorption (Bakker and Demerouti, 2008; González-Romá et al., 2006; Schaufeli et al., 2002); Such experiences are realised by immersion in research, a feeling of time passing quickly, strong psychological involvement in research combined 
with a sense of significance, enthusiasm, inspiration, pride and challenge, and high levels of energy, and resulting several positive outcomes in post-PhD researcher careers (Author et al., in press; Vekkaila, et al., 2016; Shin and Jung, 2014). For example, it has been shown that emotional support is associated with experiencing dedication, motivation and joy by Post- $\mathrm{PhD}$ researchers in STEM disciplines, and that receiving informational and instrumental support enabled Post-PhD researchers to meet the demands of academic work (Vekkaila et al., 2016). The findings further imply that researcher community and supervisory support is likely to reduce Post-PhD researcher's risk for experiencing burnout (Bakker, et al., 2008; Maslach and Leiter, 2005) resulting from long term exposure to extensive work-related stress (Maslach et al., 2001).

Researcher community, including the supervisor(s)', does not, however always provide optimal support for post-PhD researchers. In fact, lack of support from researcher communities has been more frequently reported than support (Cantwell and Lee, 2010) To develop burnout, the following are necessary: exhaustion, characterized by a lack of emotional energy, and feeling strained and tired at work, and cynicism, comprising of losing interest in one's work and feeling that it has lost its meaning; as well as distancing oneself from the work are necessary (Leiter, 1993; Maslach, 2003; Maslach and Leiter, 2008). Lack of support, mismatched or inadequate support are identified as sources of cynicism and distress among Post-PhD researchers (Vekkaila et al., 2016).

The findings imply that social support is likely to hold significant potential for promoting not only Post-PhD researcher's career development and enhanced research engagement, but also in buffering risk for experiencing burnout and prevent career abandonment. Therefore, not only should institutions provide functional forms and sources of social support, but also Post-PhD researchers themselves should be encouraged to (learn how to) seek and use as well as offer social support in order to utilize this resource in their work. This, however, means we need a greater understanding of how researchers characterize their social support profiles, and the various positive and negative attributes associated with the profiles.

\begin{abstract}
Aim
The study aimed to gain a better understanding of the function of social support among Post-PhD researchers and the interrelations between social support profiles, experienced research engagement, burnout and abandonment intentions. The following hypotheses were addressed:
\end{abstract}


H1: Different kinds of social support profiles in terms of researcher community and supervisory support can be detected among Post-PhD researchers.

$\mathrm{H} 2$ : There is variation between the profiles in terms of research group status, disciplinary background and gender.

H3: The social support profiles differ from each other in terms of research engagement, experienced burnout, satisfaction with post-doctoral research, abandonment intentions, and source of funding.

\section{Methods}

\section{Participants}

Altogether, 282 Post-PhD researchers from research intensive universities the UK $(n=98)$ and Spain $(n=184)$ participated in the study (see more detail about sampling strategy in Authors, 2016). Social scientists represented $2 / 3(n=195)$ and scientists $1 / 3(n=87)$. Their mean age was 35.9 , a bit over half (53.0 \%) were female. The mean time for completing the doctoral degree was 5.2 years. $81 \%$ had completed their doctoral thesis in the form of a monograph and $19 \%$ as article compilation. The mean time since graduation was 3.5 years, with the majority of participants being less than five years from earning the doctoral degree $(56,4 \%)$. They were typically either salaried researchers $(47 \%)$ or held competitive wards $(36.5 \%)$. Only 5\% were employed outside the university and $11.5 \%$ were unemployed at the time of the data collection. Two-fifths reported working primarily alone (41.5\%), as did those working both alone and within a group (43.1\%), whereas a much smaller group of the participants reported working in a research group (15.4\%).

Post-PhD experience-survey

The data were collected by e-mail through an online survey in winter 2014- 2015. Post-PhD experience - survey (Author, et al., in press) included Likert-type statements and open-ended questions. In this study, we utilized data from the scales on supervisory and researcher community support (9 items) entailing supervisory support (4 items), and researcher community support (5 items) (adapted from Author, et al., 2015), abandonment intentions (one item), experienced burnout (total 8 items), including cynicism (4 items) and exhaustion (4 items), research engagement (5 
items) (see more detailed information in Castello, et al., in press), satisfaction with post-doctoral work (1 item) (see scales in Table 1) and research group status (three choices alone, group and both) and source of funding All the scales were measured using a 7-point scale $(1=$ unsatisfied/strongly disagree, $7=$ completely satisfied/fully agree) (adapted from Author, et al., 2015; 2012). The survey was available in Spanish, Catalan and English. It was piloted before the data collection. It took 15 to 20 minutes to complete the survey. All the participants received written information about the project and gave their consent to participate according to the research ethics clearance procedures in the respective jurisdictions ${ }^{2}$. Where data were missing for key variables, Post-PhD researchers were excluded from the analysis.

\section{SET TABLE HERE 1}

\section{Analysis}

To explore the underlying factor structure of the supervisory and researcher community support scale, burnout scale, and research engagement scale, a series of exploratory factor analyses (EFA) using the ML extraction method with both varimax and direct oblimin rotations were conducted. Subsequently, separate EFA models using the Spain and UK sub-samples were created with the same scales to examine differences in factorial structures between nationalities. The results suggested that two factors in the supervisory and researcher community support scales (researcher community support and supervisory support), explaining $70.6 \%$ of the variance, should be retained. As for burnout, a bifactorial solution (cynicism and exhaustion), explaining 55.9\% of the variance, appeared to be most plausible. For research engagement, unifactorial solution was clearly the best fit, explaining $73.7 \%$ of the variance of the scale variables.

To divide the sample into meaningful subgroups according to the researcher community support and supervisory support, K-means cluster analysis was carried out. In the K-means cluster procedure the number of clusters is chosen by the researcher and cases are grouped into the cluster with the closest center. Cluster solutions with two and three clusters were calculated; however, the two-cluster solution gave the most homogeneous profiles and was in line with the theoretical presumptions. Once clusters were identified, their key characteristics were examined using a scatterplot and other correlational techniques ${ }^{3}$. The average scores of groups were compared using t-tests and Chi-square tests of independence were used when comparing the groups on nominal variables.

\footnotetext{
${ }^{2}$ The project was approved by the Ethics Committee of the University of name omitted for the blind review (CERURL-2013_005) and by the Spanish Ministry of Economy and Competitiveness (CSO2013-41108-R).

${ }^{3}$ Scales measured two primary sources of support entailing instrumental and emotional support.
} 


\section{Results}

On average post-PhD researchers reported receiving high levels of researcher community and supervisory support combined with high research engagement, satisfaction with their post-doctoral work and low levels of cynicism. At the same time they reported suffering average levels of exhaustion

\section{SET TABLE 2 HERE}

There were no statistically significant differences between Spanish and UK researchers in the variables, except for the experienced engagement in research $(t(280)=2.10, p<.05)$. Spanish postPhD. researchers $(M=5.55, S D=1.35)$ experienced slightly more research engagement than their counterparts in UK $(M=5.21, S D=1.15)$.

\section{Post-PhD researchers' researcher community and supervisory support profiles}

Two distinctive researcher community and supervisory support profiles were identified. The first cluster culled from our analysis was Adequate Support. It was the most common profile among the post- $\mathrm{PhD}$ researchers representing $80 \%(n=156)$ share of our sample. Post- $\mathrm{PhD}$ researchers displaying the adequate support profile reported high levels of both researcher community and supervisory support (see Figure 1).

\section{SET FIGURE 1 HERE}

The second profile Reduced Support presented one-fifth $(n=39,20.0 \%)$ of the post-PhD researchers in the sample. The Reduced Support profile holders showed less supervisory and researcher community support than their counterparts holding Adequate Support profiles. Moreover, the analysis indicated that when supervisory support increased, the variation in community support decreased. Accordingly, the data supported Hypothesis one.

Variation between the profiles in terms of research group status, disciplinary background and gender

Further investigation showed that Post-PhD researchers within the Adequate Support profile were more likely to work in research groups or both alone and in the group, than those working on their 
own $\left(\chi^{2}(1, N=191)=5.55, p<.05\right)$. Moreover, post-PhD researchers in sciences were more likely to be within the reduced support profile than their counter partners in the social sciences $\left(\chi^{2}(1, N=\right.$ $195)=8.03, p<.01)$. Both differences were statistically significant. Gender was not, however, related to cluster membership $\left(\chi^{2}(1, N=185)=.27, p=.606\right)$. Statistically significant differences were not detected either in cluster memberships between Spanish and UK Post-PhD researchers $\left(\chi^{2}(1, N=195)=1.43, p=.233\right)$. Accordingly Hypothesis 2 was only partly confirmed.

Social support profiles and research engagement, experienced burnout, abandonment intentions and source of funding.

Post-PhD. researchers within the Adequate Support profile experienced less cynicism $(t(51.03)=-$ $3.08, p<.01)$, were more engaged in their research $(t(44.39)=3.49, p<.01$ and more satisfied with their post-PhD work $(t(47.28)=5.78, p<.001)$ than post- $\mathrm{PhD}$ researchers within the Reduced Support profiles. However, no statistically significant differences between the profiles were detected in experienced exhaustion.

\section{SET FIGURE 2 HERE}

Cluster membership was related to abandonment intentions $\left(\chi^{2}(1, N=194)=15.74, \mathrm{p}<.001\right)$. Those Post-PhD researchers within the Reduced Support profile $(61.5 \%)$ were more likely to consider abandoning their post doc work than researchers within the adequate support profile (27.7\%). There were no statistically significant associations between the cluster membership and the source of funding. Thus, Hypothesis 3 was only partly confirmed.

\section{Discussion}

Results in light of prior research

Although prior research has identified supervisory and researcher community support as central determinants for post-PhD experience, this is among the first studies applying a person-centered approach and a cross-cultural design to exploring Post-PhD researchers' social support profiles and their association with research engagement, experienced burnout, satisfaction with Post-PhD researcher work, abandonment intentions and source of funding. 
The results confirmed the findings of prior studies by showing that social support is a central determinant for positive Post-PhD experience and researcher productivity (Castello, McAlpine and Pyhältö, submitted; Horta, 2009; Jackson \& Michelson, 2015; McAlpine, 2014; Puljak and Sharif, 2009; Åkerlind, 2005; 2009). However the findings go further.

Two distinctive social support profiles were identified. The majority of Post-PhD researchers displayed an Adequate Support profile whereas a minority displayed a Reduced Support profile. Those Post-PhD researchers within the Adequate Support profile experienced more research engagement and were more satisfied with their Post-PhD work. They were less likely to consider abandonment and suffered less cynicism than their counterparts within the Reduced Support profile. Further, no differences were detected between UK and Spanish Post-PhD researcher support profiles. Spanish researchers however, experienced slightly more engagement than their UK counterparts, a finding whose meaning we are still exploring. Nevertheless, the finding provides one of the first confirmations of the cross-cultural influence of social support, implying that despite differences in Post-PhD systems and cultures in the UK and Spain, social support is perceived similarly by the Post- $\mathrm{PhD}$ researchers, and is associated with positive Post- $\mathrm{PhD}$ researcher experience. Further, the evidence suggests that the work stressors remain constant across borders.

Another interesting finding was the relation between increased supervisor support and reduced variation in community support. While further research is called for, we propose two explanations: first of all, when supervisory support was good, individuals might have wanted to focus on accessing and using the supervisor's network while they could, i.e., since the position might be a short one; another possibility is that they felt so well supported there was no need to seek other support. Still, how these researchers interpret community support (Are individuals mostly included or organizations? What are the aims and function of this support?) deserves further attention.

Further analyses showed that Post-PhD researchers who were at least partly involved in a research group were more likely to fall within the Adequate Support profile than those working primarily alone. A reason for this may be that working in the research group provides more opportunities for researcher collaboration and networking. However, somewhat unexpectedly the source of funding was not associated with experienced support. A further reason might be that the source of funding does not count in terms of social support as much as the fact that one has funding. Further, regardless of source of funding, it would typically be for a short period so the sense of insecure income could remain (Author, 2016). The results imply that structures that provide opportunities for 
better post-PhD researcher integration into the researcher community are likely to enhance experienced supervisory and researcher community support.

Results also showed that post-PhD researchers in the social sciences were more likely to fall within the Adequate Support profile than their counterparts in the natural sciences. This finding is striking since prior studies of doctoral researchers in STEM disciplines suggest they are more satisfied with their supervision, and researcher community support, entertain higher $\mathrm{PhD}$ completion rates and shorter completion time than their counter partners in the social sciences or in humanities (Gardner, 2009; 2010; Visser et al., 2007; Wright and Cochrane 2000; Author, et al., 2015). So, perhaps changing roles, i.e., moving from institutional status as a 'learner' to a 'worker,' changes the nature of the support on offer. Further, since post- $\mathrm{PhD}$ researchers are often mobile, including internationally (McAlpine, et al., 2016), they will find themselves in new institutions so not yet with developed local support. The finding also contradicts the common assumption that being a scientist, whether $\mathrm{PhD}$ or post- $\mathrm{PhD}$, includes working in a supportive team environment (Cumming, 2009), and we have some evidence that a team environment can be toxic for both $\mathrm{PhD}$ and post$\mathrm{PhD}$ researchers (Author, 2016). In other words, we cannot assume that being in a group automatically provides support. Another reason for the discrepancy may be that prior studies have typically adopted a variable-based approach in exploring disciplinary differences; however, extensive variation between the individuals within the discipline in experienced social support is likely to occur. This type of individual variation in experienced support does not surface in a variable-based approach, but becomes observable when adopting a person-centered approach.

Experienced exhaustion was a general phenomenon confirming previous studies; interestingly though it was not related to social support profiles. This suggests that social support is not the primary determinant of experienced exhaustion, and that exhaustion is primarily determined by other work stressors. This further, implies that post- $\mathrm{PhD}$ researchers may develop exhaustion even if adequate support is provided. Accordingly, our results suggest that cynicism towards post-PhD work experienced by Post-PhD researchers is more socially determined than exhaustion, i.e., likely increases as a result of reduced support. There are some indicators that workload may be a more central determinant for exhaustion; however further studies are needed to explore this hypothesis. Moreover, we found no gender differences in the support profiles of the Post-PhD researchers, although in prior studies many differences between female and male $\mathrm{PhD}$ degree holders have been detected, more often to the benefit of males (e.g., Deem and Brehony, 2000; Fox, 2005). 


\section{Methodological limitations}

Because of the cross-sectional design, it is not possible to discern causal relationships. Also, due to the small number of members in the reduced support group the power of statistical tests is limited and only relatively clear group differences could be detected. The analysis focused on the researcher community and have not included information on personal life support. The structure of the scales and items of the questionnaire did not allow us to differentiate among types of social support (emotional, instrumental or informational) but on the sources of the support.

\section{Implications for developing post-PhD researcher support}

The results imply that experiencing supervisory and researcher community support for post- $\mathrm{PhD}$ researchers promotes researcher engagement, satisfaction with post-PhD work and reduces risk for experiencing cynicism. What does this mean for both post-PhD researchers and the institutions in which they work? Recognizing the importance of supervisory and researcher community support provides a grounding for developing post- $\mathrm{PhD}$ education and post- $\mathrm{PhD}$ careers. In other words, we suggest universities conceive the role of post-PhD researchers as developmental calling for a continuation of the support offered during the $\mathrm{PhD}$ rather than treating them as completely independent researchers. Although the majority of post- $\mathrm{PhD}$ researchers' entertained adequate support profiles, still a significant number experienced insufficient support. Hence, it would be beneficial to identify researchers at risk as early as possible and assist them to develop support strategies, to help avoid their developing cynicism and a reduced sense of research engagement which can have severe intellectual and personal costs, and lead to abandonment intentions. Such support should focus on opportunities for networking and researcher collaboration such as coauthoring, and consortium building. However, to be effective, this support needs to be matched to individual needs which could promote a dialogue with post- $\mathrm{PhD}$ researchers themselves.

Also post-PhD researchers themselves can learn how to actively seek as well as provide support for each other and learn to cope and solve conflicts more independently within their communities. A prior study showed that although early career post- $\mathrm{PhD}$ researchers perceived received support as highly significant for their study progress, they provided support for others less often than they receive it (Vekkaila et al., 2016). This implies that opportunities and arenas to learn how and when to provide reciprocal support are needed. This includes identifying and skillfully using the potential sources of support available (Author, 2012). Such a perspective means starting earlier with doctoral students: supporting their agentic behavior in terms of social support, from the very beginning of 
doctoral studies, since their ability to engage in agentic behaviors then is likely to be highly influential for their future academic careers.

\section{Conclusion}

The results of this study suggest the value of future research using a person-centered approach, and when possible a cross-cultural design. Further, future research should begin to differentiate forms of support, i.e., emotional, informational and instrumental, as well as more finely categorize sources of support beyond supervisor(s) and others. Such an approach would enable a richer understanding of the relative influences of social support on engagement or exhaustion, burnout and potential abandonment. We also wonder the extent to which frequency of experience of social support plays a role. All this suggests there remain many interesting questions for researchers to take up.

\section{References}

Auriol, L. (2010), "Careers of Doctorate Holders: Employment and Mobility Patterns". OECD Science, Technology and Industry Working Papers. doi: 10.1787/5kmh8phxvvf5-en

Bakker, A. B., \& Demerouti, E. (2008), “Towards a model of work engagement" Career Development International, Vol. 13, pp. 209-223. doi: $10.1108 / 13620430810870476$

Baker, V., \& Pifer, M. (2015), "Antecedents and outcomes: theories of fit and the study of doctoral education” Studies in Higher Education, Vol. 40, pp. 296-310. doi: 10.1080/03075079.2013.823936

Bakker, A. B., Schaufeli, W. B., Leiter, M. P., \& Taris, T. W. (2008), "Work engagement: an emerging concept in occupational health psychology" Work and Stress, Vol. 22, pp. 187-200. doi:

$10.1080 / 02678370802393649$

Billett, S. (2001). "Learning through work: workplace affordances and individual engagement" Journal of workplace learning, Vol. 13, pp. 209-214. doi: 10.1108/EUM0000000005548

Boeren, E., Lokhtina-Antoniou, I.; Sakurai, I.; Herman, C., \& McAlpine, L. (2015), Mentoring: A review of early career researcher studies. Frontline Learning Research. 3 (3), 68-80.

Browning, L., Thompson, K., \& Dawson, D. (2011), "Developing the next generation of reserach leaders: Understanding the path to shaping the future" Acta Academica Supplementum, Vol. 2, pp. 127-148.

Cantwell, B., \& Lee, J. (2010), "Unseen workers in the academic factory: Perceptions of neoracism among international postdocs in the United States and the United Kingdom" Harvard Educational Review, Vol. 80, pp. 490-517. doi: 10.17763/haer.80.4.w54750105q78p451

Authors (in press)

Chan, D. W. (2002), "Stress, Self-Efficacy, Social Support, and Psychological Distress among Prospective Chinese Teachers in Hong Kong” Educational Psychology, Vol. 22, pp. 557-569. doi: $\underline{10.1080 / 0144341022000023635}$

Chen, S., McAlpine L., \& Amundsen, C. (2015), "Postdoctoral positions as preparation for desired careers: a narrative approach to understanding postdoctoral experience" Higher Education Research \& Development, Vol. 34, pp. 1083-1096. doi: 10.1080/07294360.2015.1024633 
Cobb, S. (1976), "Social Support as a Moderator of Life Stress" Psychosomatic Medicine, Vol. 38, No. 5, pp. 300-314.

Cohen, S. \& McKay, T. A. (1984), "Stress, social support, and the Buffering Hypothesis: A theoretical analysis" In A. Baum, S. E. Taylor \& J. E. Singer (Eds.), Handbook of psychology and health. Hillsdale: Lawrence Erlbaum. pp. 253-267

Cohen, S., \& Syme, L. (1985), "Issues in the study and application of social support" In S. Cohen and L. Syme (Eds.), Social support and health. San Francisco: Academic Press. pp. 3-22

Cumming, J. (2009), "The doctoral experience in science: Challenging the current orthodoxy." British Educational Research Journal. Vol. 35, No. 6, pp. 877-890

Deem, R., \& Brehony, K. (2000). "Doctoral Students' Access to Research Cultures-are some more unequal than others?" Studies in Higher Education, Vol. 25, No 2, pp. 149-165.

Dever, M., Boreham, P., Haynes, M., Kubler, M., Laffan, W., Behrens, K., \& Western, M. (2008), “Gender differences in early post-PhD employment in Australian Universities: The influence of $\mathrm{PhD}$ experience on women's academic careers (Final report)" St Lucia: University of Queensland.

Gardner, S. (2009), "Student and faculty attributions of attrition in high and low completing doctoral programs in the United States" Higher Education. Vol. 58, No. 1, pp. 97-112.

Gardner. S. (2010), "Contrasting the Socialization Experiences of Doctoral students in High- and Low- Completing Departments: A Qualitative Analysis of Disciplinary Contexts at One Institution" Journal of Higher Education Vol 81 no. 1: 61-81.

González-Romá, V., Schaufeli W. B., Bakker, A. B., \& Lloret, S. (2006), "Burnout and work engagement: Independent factors or opposite poles?" Journal of Vocational Behavior, Vol. 68, pp. 165-174. doi: $\underline{10.1016 / j . j v b .2005 .01 .003}$

Helgeson, V., \& Gottlieb, B. (2000), "Social Support Measurement and Intervention: A guide for health and social scientists" In S. Cohen, L. Underwood \& B. Gottlieb. Support groups. New York: Oxford university press. pp. 221-245

Horta, H. (2009), "Holding a post-doctoral position before becoming a faculty member: does it bring benefits for the scholarly enterprise?" Higher Education, Vol. 58, pp. 689-721. doi: 10.1007/s10734-009-9221-1

House, J. (1981), “Work stress and social support” Addison-Wesley Educational Publishers Inc .

Jackson, D., \& Michelson, G. (2015). "Factors influencing the employment of Australian PhD graduates" Studies in Higher Education, Vol. 40, pp. 1660-1678. doi: 10.1080/03075079.2014.899344

Kinman, G., \& Court, S. (2010), "Psychosocial hazards in UK universities: adopting a risk assessment approach" Higher Education Quarterly, Vol. 64, pp. 413-428. doi: 10.1111/j.1468-2273.2009.00447.x

Laudel, G., \& Gläser, J. (2008), "From apprentice to colleague: The metamorphosis of Early Career Researchers" Higher Education, Vol. 55, pp. 387-406. doi: 10.1007/s10734-007-9063-7

Leiter, M. (1993), "Burnout as a developmental process: consideration of models." In W. B. Schaufeli, C. Maslach, \& T. Marek (Eds.), Professional burnout. Philadelphia, PA: Taylor \& Francis. pp. 237-250

Maslach, C. (2003), "Job burnout: new directions in research and interventions" Current Directions in Psychological Science, Vol. 12, pp. 189-192. doi: 10.1111/1467-8721.01258 
Maslach, C., \& Leiter, M. P. (2005), "Banishing burnout: Six strategies for improving your relationship with work" San Francisco: Jossey-Bass.

Maslach, C., \& Leiter, M. P. (2008), "Early predictors of job burnout and engagement" Journal of Applied Psychology, Vol. 93, pp. 498-512. doi: 10.1037/0021-9010.93.3.498

Maslach, C., Schaufeli,W., \& Leiter, P. (2001), "Job burnout: new directions in research and intervention" Current Directions in Psychological Science, Vol. 12, pp. 189-192. doi: 10.1111/1467-8721.01258

Author (2016)

Author (2014)

Author (2015)

Author (2016)

Author (2015)

Author (2016)

Pearson, M., Cumming, J., Evnas, T., Macauley, P., \& Ryland, K. (2011), "How shall we know them? Capturing the diversity of difference in Australian doctoral candidates and their experiences" Studies in Higher Education, Vol. 36, No. 5, pp. 527-542.

Platow, M. (2012), "PhD experience and subsequent outcomes: a look at self-perceptions of acquired graduate attributes and supervisor support" Studies in Higher Education, Vol. 37, pp. 103-118. doi: $10.1080 / 03075079.2010 .501104$

Puljak, L., \& Sharif, W. (2009), "Postdocs' perceptions of work environment and career prospects at a US academic institution" Research Evaluation, Vol. 18, pp. 411-415.doi: 10.3152/095820209X483064

Author (2012)

Author (2012)

Author (2015)

Rybarczyk, B., Lerea, L., Lund, P. K., Whittington, D., \& Dykstra, L. (2011), "Postdoctoral Training Aligned with the Academic Professoriate" Professional Biologist, Vol. 61, pp. 699-705. doi: $\underline{10.1525 / \text { bio.2011.61.9.8 }}$

Scaffidi, A., \& Berman, J. (2011), “A positive postdoctoral experience is related to quality supervision and career mentoring, collaborations, networking and a nurturing research environment" Higher Education, Vol. 62, pp. 685-698. doi: 10.1007/s10734-011-9407-1

Schaufeli, W. B., Salanova, M., González-Romá, V., \& Bakker, A. B. (2002), “The measurement of engagement and burnout: A two sample confirmatory factor analytic approach" Journal of Happiness Studies, Vol. 3, pp. 71-92. doi:10.1023/A:1015630930326

Shing, J. C., \& Jung, J. (2014), Academics job satisfaction and job stress across countries in the changing academic environments. Higher Education, Vol. 67, pp. 603-620. Doi: 10.1007/s10734-013-9668-y

Veikkaila, J., Virtanen, V., Taina, J. \& Pyhältö, K. (in press), “The function of social support in engaging and disengaging experiences among post $\mathrm{PhD}$ researchers in STEM disciplines" Studies in Higher Education. Vol. 5, pp. 222-235. Doi: 10.5430/ijhe.v5n2p222 
Virtanen, V., Taina, J., \& Pyhältö, K. (2016), "What disengages doctoral students in the biological and environmental sciences from their doctoral studies?" Studies in Continuing Education, pp. 1-16, Doi: 10.1080/0158037X.2016.1250737

Visser, S. M., Luwel, M., \& Moed, F. H. (2007), "The Attainment of Doctoral Degrees at Flemish Universities: A Survival Analysis". Higher Education, Vol. 54, pp. 741-757. doi: 10.1007/s10734-006-90219

Väisänen, S., Pietarinen, J., Pyhältö, K., Toom, A., \& Soini, T. (2016), "Social support as a contributor to student teachers' experienced well-being” Research Papers in Education, pp. 1-15. doi:

$10.1080 / 02671522.2015 .1129643$

White, G. (2015), "Supporting early career researchers in higher education in Europe: The role of employers and trade unions" Project Report. Available at:

http://gala.gre.ac.uk/13318/1/13318 White_Supporting_early_career_researchers_(rep.)_2015.pdf (accessed 9 September 2016)

Wright, T. \& Cochrane, R. (2000), "Factors Influencing Successful Submission of PhD Theses" Studies in Higher Education, Vol. 25, pp. 181-195. doi: 10.1080/713696139

Åkerlind, G. (2005), "Postdoctoral researchers: roles, functions and career prospects" Higher Education Research \& Development, Vol. 24, pp. 21-40. doi: 10.1080/0729436052000318550

Åkerlind, G. (2009), "Postdoctoral research positions as preparation for an academic career" International Journal of research, Vol. 1, pp. 84-97. doi: 10.1108/1759751X201100006 


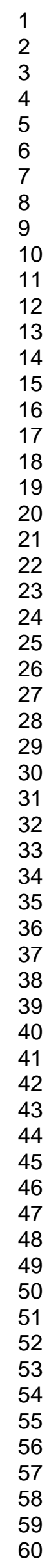

https://mc.manuscriptcentral.com/eer 
Table 1. Scales, and items

\begin{tabular}{|c|c|}
\hline Scale & Items \\
\hline Researcher community support & $\begin{array}{l}\text { I feel that the other members of my research community } \\
\text { appreciate my work. } \\
\text { I feel accepted by my research community. } \\
\text { There is a good sense of collegiality among the researchers } 1 \\
\text { interact with. } \\
\text { I receive encouragement and support from the other } \\
\text { researchers. } \\
\text { My expertise is put use in the research community. }\end{array}$ \\
\hline Supervisory support & $\begin{array}{l}\text { I feel that my supervisor(s) appreciate my work. } \\
\text { I feel appreciated by my supervisor(s). } \\
\text { I receive encouragement and personal attention from my } \\
\text { supervisor(s). } \\
\text { I can openly discuss any problems related to my post-doc } \\
\text { research with my supervisor(s). }\end{array}$ \\
\hline \multicolumn{2}{|r|}{ (1) } \\
\hline Cynicism & $\begin{array}{l}\text { I feel my post-doc work is useless. } \\
\text { I feel that I am losing interest in my post-doc work. } \\
\text { I have difficulties in finding any meaning to my post-doc } \\
\text { work. } \\
\text { I used to have higher expectations of my post-doc work than } \\
\text { I do now. }\end{array}$ \\
\hline & $\begin{array}{l}\text { I feel overwhelmed by the workload of my post-doc work. } \\
\text { I often sleep badly because of matters related to my post-doc } \\
\text { work. } \\
\text { I brood over matters related to post-doc work a lot during } \\
\text { my free time. }\end{array}$ \\
\hline Exhaustion & $\begin{array}{l}\text { The pressure of my post-doc work causes me problems in my } \\
\text { close relationships with others. }\end{array}$ \\
\hline Research engagement & $\begin{array}{l}\text { When I conduct research, I feel that I am bursting with } \\
\text { energy } \\
\text { When doing my research, I feel vigorous } \\
\text { I am enthusiastic about my research } \\
\text { My research inspires me } \\
\text { I feel happy when I start working on my research }\end{array}$ \\
\hline Satisfaction with post-doctoral work & Are you satisfied with your post-doc work? \\
\hline
\end{tabular}


Table 2 Descriptive for supervisory support, community support, cynicism, exhaustion, experienced engagement in post-doctoral work $(N=194-195)$

\begin{tabular}{lcccccc}
\hline Items/Scales & $\begin{array}{c}\text { N of } \\
\text { items }\end{array}$ & Alpha & $\boldsymbol{M}$ & SD & Min & Max \\
\hline Supervisory support & 4 & .95 & 5.07 & 1.81 & 1 & 7 \\
Researcher community support & 5 & .88 & 5.11 & 1.25 & 1 & 7 \\
Cynicism & 4 & .87 & 2.92 & 1.58 & 1 & 7 \\
$\begin{array}{l}\text { Exhaustion } \\
\text { Experienced engagement in }\end{array}$ & 4 & .88 & 3.54 & 1.42 & 1 & 7 \\
$\begin{array}{l}\text { post-doctoral work } \\
\text { Satisfaction with post- doctoral }\end{array}$ & 5 & .93 & 5.43 & 1.29 & 1 & 7 \\
work & 1 & - & 4.85 & 1.68 & 1 & 7 \\
\hline
\end{tabular}




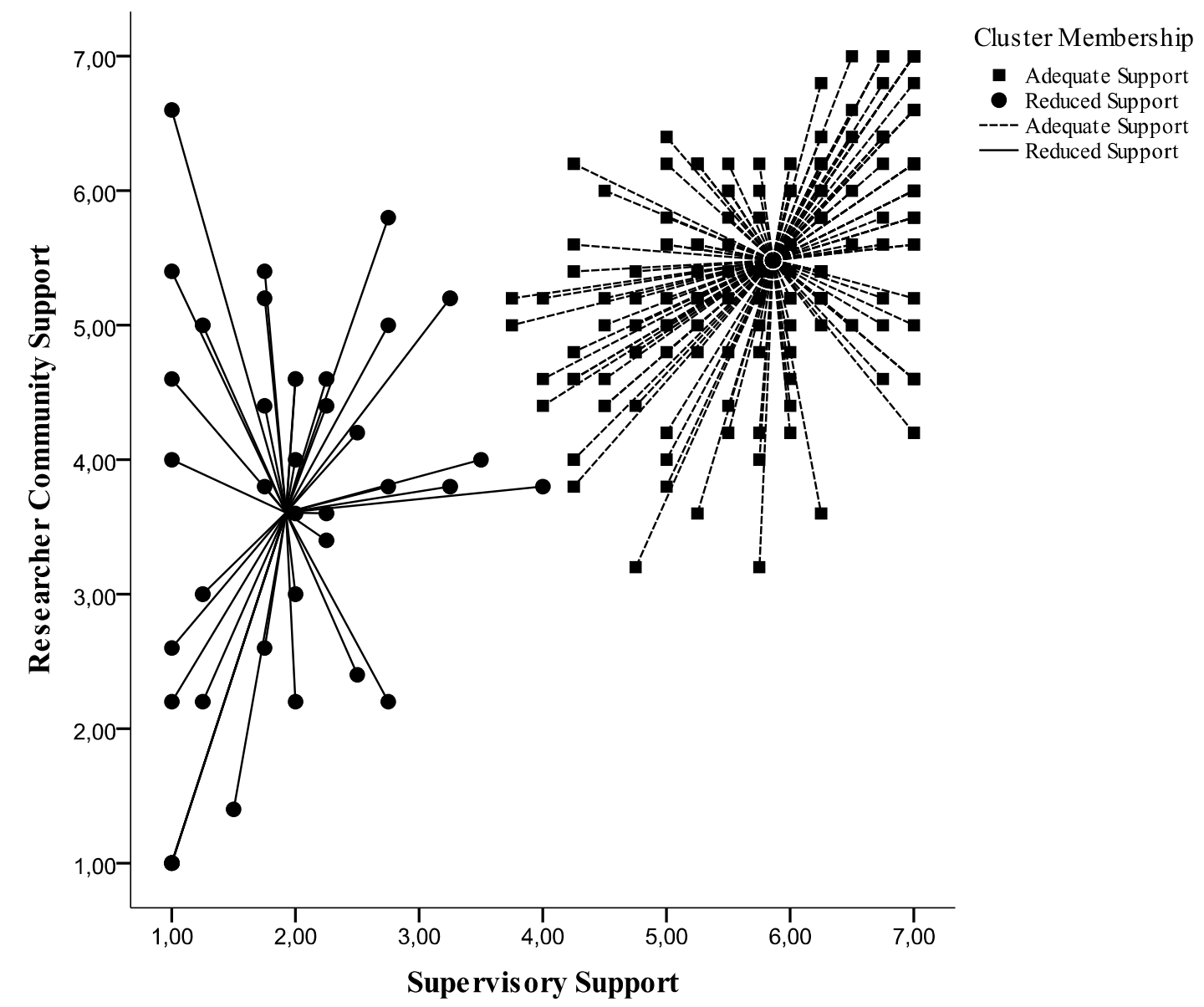

Figure 1 . The researcher community and supervisory support profiles 


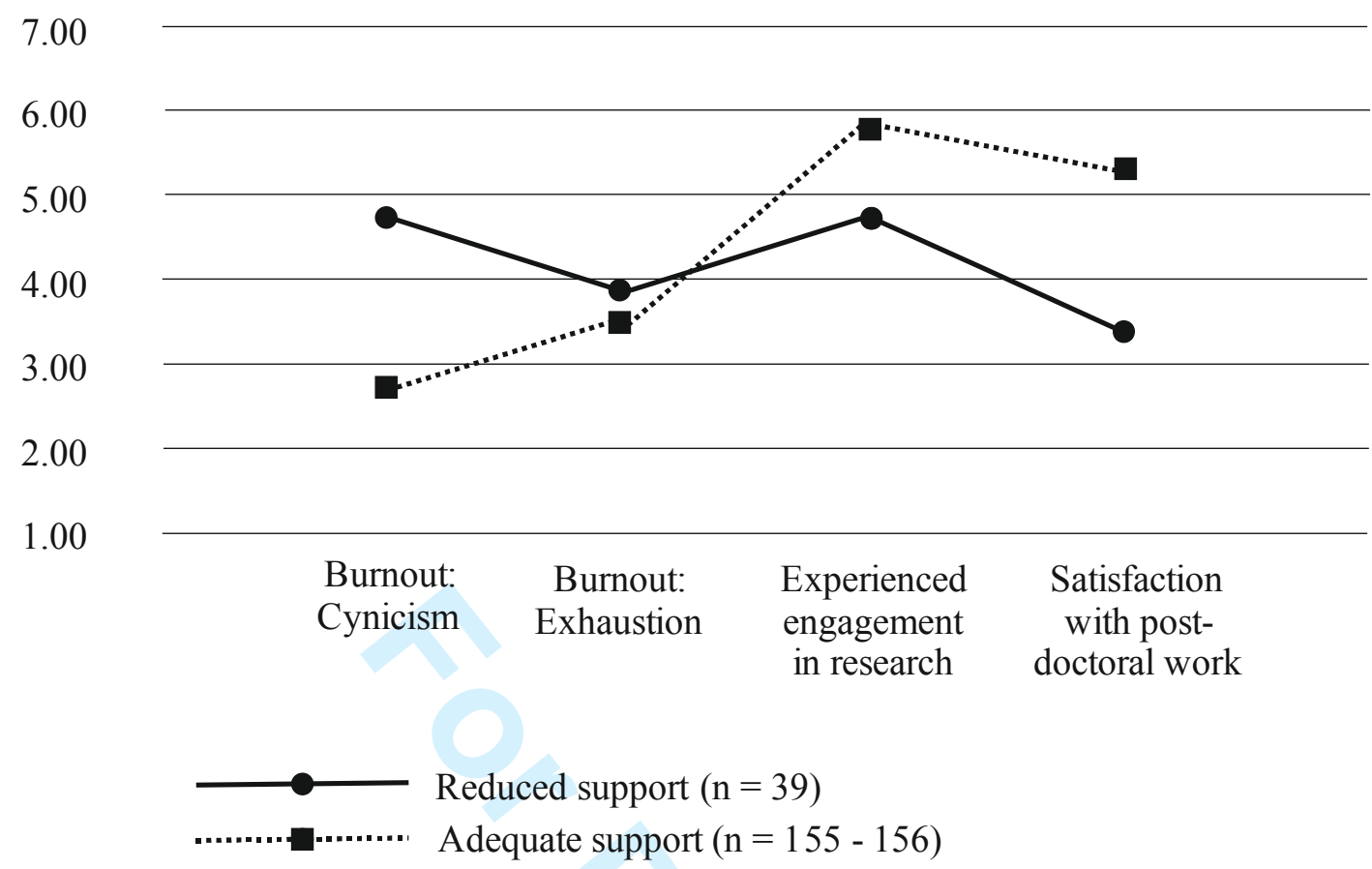

Figure 2. Interrelation between the support profiles and cynicism, exhaustion, research engagement, and satisfaction with post-doctoral work. 